\title{
MALIGNANT TRANSFORMATION OF MULTIPLE ENCHONDROMAS OF THE HAND
}

\section{INTRODUCTION:}

Dyschondroplasia refers to clinical syndromes characterized by abnormal cartilaginous growth in bone. One form, enchondromas, are benign tumors occurring within the medulla. They most commonly affect the small bones of the hand in individuals between the age of 10 and 30 years. 1 We report a dramatic and debilitating case of enchondromas occurring at multiple sites in a patient, known as enchondromatosis or Ollier's disease, with secondary malignant change.

\section{CASE HISTORY:}

A 26-year-old male Tibetan presented to our remote hospital at $3900 \mathrm{~m}$ near Mt. Everest with several deforming growths on the dorsum of his left hand. He reported no pain or tenderness. The masses had grown slowly in size since first noticed at the age of 6 years. He was otherwise in good health.

\section{Review of systems was unremarkable:}

On examination, the man appeared well. Four large masses were obvious on the dorsum of his left hand (Figure 1). The hand was grossly deformed and only the thumb, $4^{\text {h }}$ and $5^{\text {th }}$ digits had any remaining motion. The involved $2^{\text {nd }}$ and $3^{\text {rd }}$ digits were fixed without mobility. The masses were hard, non-mobile, and clearly contiguous with the underlying bones. The second metacarpal mass measured $6.5 \mathrm{~cm}$ diameter. The $3^{\text {rd }}$ proximal phalange mass was $5 \mathrm{~cm}$ diameter. The masses on the $2^{\text {nd }}$ proximal and middle phalanges measured $3.5 \mathrm{~cm}$ and $2.5 \mathrm{~cm}$ diameter respectively.

$\mathrm{X}$-rays of the hand revealed that the four lesions described above clearly involve the central bone and spread to completely distort the overlying cortical bone (Figure 2). Centrally the lesions appear honeycombed, having irregular radiolucent areas flecked with foci of ossification.

Biopsy of the largest lesion that involved the $2^{\text {nd }}$ metacarpal was sent for histopathologic evaluation in Kathmandu. Microscopic findings of proliferation of chondrocytes without bone formation or inflammation was consistent with benign enchondroma. However, additional histopathologic and radiographic opinions obtained from the United States suggest malignant transformation to chondrosarcoma.

Unfortunately, the patient's follow-up is delayed having returned to Tibet by foot over the $5200 \mathrm{~m}$ Nangpa La pass.

\section{DISCUSSION:}

Enchondromatosis or Ollier's disease is a non-hereditary condition thought to be the result of failure of ossification of cartilage columns in the growth plate, leading to multiple masses of cartilage in the metaphysis.2 Pathologic fractures may occur from thinning of the overlying cortex. In this particular case, the multiple sites of enchondromas resulted in marked deformity and impaired function of the involved hand, and likely malignant transformation.

Diagnosis of enchondroma is commonly made by the characteristic $\mathrm{x}$-ray appearance of irregular radiolucent areas stippled with ossification densities. Biopsy is usually only required when the lesions are painful, large or radiographic findings are questionable. 3 The x-ray appearance of chondrosarcomas are large lesions $(>5 \mathrm{~cm})$ with ill-defined margins.4 These may required multiple biopsies to confirm a malignant focus, as our case illustrates.

Malignant transformation can occur in multiple enchondromas, particularly in bones other than the hands and feet, but rarely in a single lesion.5 Therefore, repeat radiographic assessment and biopsy may be needed periodically to monitor for progression of benign appearing lesions. It is possible that our patient may only recently have had a malignant transformation given the recent enlargement of his lesions. 
Treatment of enchondromas is only necessary for larger, symptomatic lesions, and involves curettage of the lesion with bone grafting. For chondrosarcomas, wide excision is the standard as chemotherapy or radiation are generally ineffective. 6 The patient would likely benefit from a ray resection of this $2^{\text {id }}$ and $3^{\text {rd }}$ metacarpals and phalanges to remove the tumor and improve functional use of the hand.

\section{REFERENCES:}

1. Cotran SR, Kumar V, Robbins SL. Robbins Pathologic Basis of Disease, $4^{\text {th }}$ ed. Philadelphia, PA :WB Saunders Company, 1989.

2. Hill RA. Diseases of bones and joints: congenital disorders. In: Mann CV, Russell RCG, Williams NS, eds. Bailey and Love's Short Practice of Surgery, $22^{\text {nd }}$ ed. London: Chapman and Hall, 1995:294306.

3. Pritchard DJ. Tumors of bones and joints. In: Beers MH, Berkow R, eds. The Merck Manual of Diagnosis and Therapy, $17^{\text {th }}$ ed. Whitehouse Station, New jersey: Merck Research Laboratories, 1999:465-469.

4. Geirnaerdt MJ. Usefulness of radiography in differentiating enchondroma from central grade 1 chondrosarcoma. American Journal of Roentgenology 1997;169(4):1097-1104.

5. Grange WJ. Diseases of bones and joints: tumours. In: Mann CV, Russell RCG, Williams NS, eds. Bailey and Love's Short Practice of Surgery, $22^{\text {nd }}$ ed. London: Chapman and Hall, 1995:276-280.

6. Calandruccio JH, Jobe MT. Tumors and tumorous conditions of the hand. In: Camale ST, ed. Campbell's Operative Orthopedics, $9^{\text {th }}$ ed. St. Louis, MO: Mosby-Year Book, 1998;4:3711-3717. 